\title{
Metrics and Evaluation Tools for Patient Engagement in Healthcare Organization- and System-Level Decision- Making: A Systematic Review
}

\author{
Vadim Dukhanin ${ }^{1}$, Rachel Topazian $^{2,3}$, Matthew DeCamp ${ }^{3,4^{*}}$
}

\begin{abstract}
Background: Patient, public, consumer, and community (P2C2) engagement in organization-, community-, and systemlevel healthcare decision-making is increasing globally, but its formal evaluation remains challenging. To define a taxonomy of possible P2C2 engagement metrics and compare existing evaluation tools against this taxonomy, we conducted a systematic review.

Methods: A broad search strategy was developed for English language publications available from January 1962 through April 2015 in PubMed, Embase, Sociological Abstracts, PsycINFO, EconLit, and the gray literature. A publication was excluded if: (1) the setting was not healthcare delivery (ie, we excluded non-health sectors, such as urban planning; research settings; and public health settings not involving clinical care delivery); (2) the P2C2 engagement was episodic; or (3) the concept of evaluation or possible evaluation metrics were absent. To be included as an evaluation tool, publications had to contain an evaluative instrument that could be employed with minimal modification by a healthcare organization.

Results: A total of 199 out of 3953 publications met exclusion and inclusion criteria. These were qualitatively analyzed using inductive content analysis to create a comprehensive taxonomy of 116 possible metrics for evaluating $\mathrm{P} 2 \mathrm{C} 2$ engagement. 44 outcome metrics were grouped into three domains (internal, external, and aggregate outcomes) that included six subdomains: impact on engagement participants, impact on services provided by the healthcare organization, impact on the organization itself, influence on the broader public, influence on population health, and engagement cost-effectiveness. The 72 process metrics formed four domains (direct process metrics; surrogate process metrics; aggregate process metrics; and preconditions for engagement) that comprised sixteen subdomains. We identified 23 potential tools for evaluating P2C2 engagement. The identified tools were published between 1973-2015 and varied in their coverage of the taxonomy, methodology used (qualitative, quantitative, or mixed), and intended evaluators (organizational leaders, $\mathrm{P} 2 \mathrm{C} 2 \mathrm{participants,}$ external evaluators, or some combination). Parts of the metric taxonomy were absent from all tools.

Conclusions: By comprehensively mapping potential outcome and process metrics as well as existing $\mathrm{P} 2 \mathrm{C} 2$ engagement tools, this review supports high-quality P2C2 engagement globally by informing the selection of existing evaluation tools and identifying gaps where new tools are needed.

Systematic Review Registration: PROSPERO registration number CRD42015020317.

Keywords: Patient Engagement, Patient Participation, Health Systems, Health Planning, Organizational Decision-Making Copyright: (c) 2018 The Author(s); Published by Kerman University of Medical Sciences. This is an open-access article distributed under the terms of the Creative Commons Attribution License (http://creativecommons.org/licenses/by/4.0), which permits unrestricted use, distribution, and reproduction in any medium, provided the original work is properly cited.

Citation: Dukhanin V, Topazian R, DeCamp M. Metrics and evaluation tools for patient engagement in healthcare organization- and system-level decision-making: a systematic review. Int J Health Policy Manag. 2018;7(10):889-903. doi:10.15171/ijhpm.2018.43
\end{abstract}

Article History:

Received: 4 October 2017 Accepted: 28 April 2018 ePublished: 16 May 2018

*Correspondence to:

Matthew DeCamp

Email:

mdecamp1@jhmi.edu

\section{Introduction}

Ensuring that individuals and communities are engaged in healthcare decision-making is now widely regarded as a requirement of patient centered care. One part of engagement, enshrined as a right of all people in the 1978 Declaration of Alma-Ata, ${ }^{1}$ requires engaging patients not only in their own individual medical decisions but also in the design and implementation of healthcare services. ${ }^{2,3}$ This type of engagement is occurring globally. In the United States, some jurisdictions require patient and family advisory councils to inform individual hospital governance, ${ }^{4}$ major healthcare reform efforts require patient representation on governance boards, ${ }^{5}$ and many healthcare organizations and systems see patient engagement as the right thing to do (a recurring theme since at least the 1970s) ${ }^{6-9}$ In the United Kingdom, ${ }^{10-12}$ Canada, ${ }^{13-15}$ Australia, ${ }^{16,17}$ and New Zealand, ${ }^{18}$ there has also been systematic public involvement in healthcare decisionmaking via regional or local health advisory councils, committees, boards or citizen juries. Public engagement in health sector priority-setting has also been mandated or promoted in low- and middle-income countries. ${ }^{19-22}$

Despite increasing attention to patient engagement in the design and implementation of healthcare services, there is both a greater need for formal engagement evaluation ${ }^{23}$ and little agreement on how to do so. Existing how-to guides suggest that patient engagement can contribute positively to 
health outcomes, reduce unnecessary costs, or increase trust in healthcare organizations, ${ }^{24,25}$ but real evidence of these impacts, according to literature reviews, is lacking. ${ }^{26-28}$ A 2010 review of engagement in healthcare policies and programs concluded that existing evaluations narrowly focus on shortterm impact and proxy or surrogate measures of perceived impact. $^{29}$

Given the evidence gap and the need to update existing reviews, we conducted a systematic review of metrics to evaluate patient, public, consumer and community (P2C2) engagement in organization-, community-, and systemlevel healthcare decision-making. We defined P2C2 engagement as a continuous systematic effort to incorporate the needs, values, and preferences of the P2C2 engagement participants into decision-making. Though there may be differences between patients, the public, consumers, and the community in concept, in practice healthcare organizations may use the terms interchangeably when engaging those stakeholders in decision-making, and our focus was upon what is common to all those engagement activities - namely, the goal of incorporating those stakeholders' needs, values and preferences. In those activities, P2C2 engagement participants are involved as stakeholder representatives of their constituents, rather than as individuals. This review focuses on engagement in organization-, community-, and system-level healthcare decision-making as distinct from patient engagement in their individual personal medical decisions. ${ }^{2,3}$ Our objectives were (1) to create a taxonomy of possible P2C2 engagement evaluation metrics using an inductive qualitative analysis of the literature and then (2) to compare existing $\mathrm{P} 2 \mathrm{C} 2$ engagement evaluation tools against this taxonomy.

\section{Methods}

Identification of Publications

The nature of our subject matter required a broad search strategy within the published and gray literature. We conducted a search for publications available in English from January 1, 1962 through April 20, 2015 in PubMed, Embase, Sociological Abstracts, PsycINFO, and EconLit with Full Text. Terminology surrounding P2C2 "engagement" may be imprecise; therefore, we designed our search to cast a wide net, then relied upon our inclusion/exclusion criteria to identify target publications. Search terms were identified via consultations with an informationist and through an iterative process of search yield analyses. The final search included three concept blocks: (1) P2C2 engagement; (2) decisionmaking; and (3) healthcare planning.

The first block included 125 search terms, which combined (i) "patient," "consumer," "stakeholder," "community," "public," and related words with (ii) "engagement," "participation," "involvement," "representation," "advocacy," and related words. The second block included 40 search terms, such as "decisionmaking," "clinical governance," "policy-making," "governing board," "participatory management," and related words. The third block included 61 search terms, which combined (i) "healthcare," "health," and "medical" with (ii) "system," "organization," "planning," "priority," and related words. For all three concept blocks we included corresponding controlled vocabulary items relevant to the particular database. To be included, a publication had to contain at least one term or controlled vocabulary item from each block. Full details of the search strategy are included in online Supplementary file 1. After combining all database search results and removing duplicates, this search yielded 3953 possible publications. Gray literature publications were identified throughout May 2015-July 2016 from sources identified during review of the published literature and via a similar search strategy of select websites. The 32 targeted websites of relevant national and international organizations are included in online Supplementary file 2. The gray literature search yielded 97 additional possible publications.

Lastly, during our full text review, in reference lists we identified 44 additional possible publications which were reviewed in full-text. This systematic review was included on May 7, 2015 in the International Prospective Register of Systematic Reviews (PROSPERO), registration number CRD42015020317.

\section{Criteria for Selection}

Figure 1 describes the publication selection process. We excluded publications whose language was not in English or whose publication type did not provide a full-text version. We included publications if their setting was healthcare administration or healthcare organization in clinical settings.

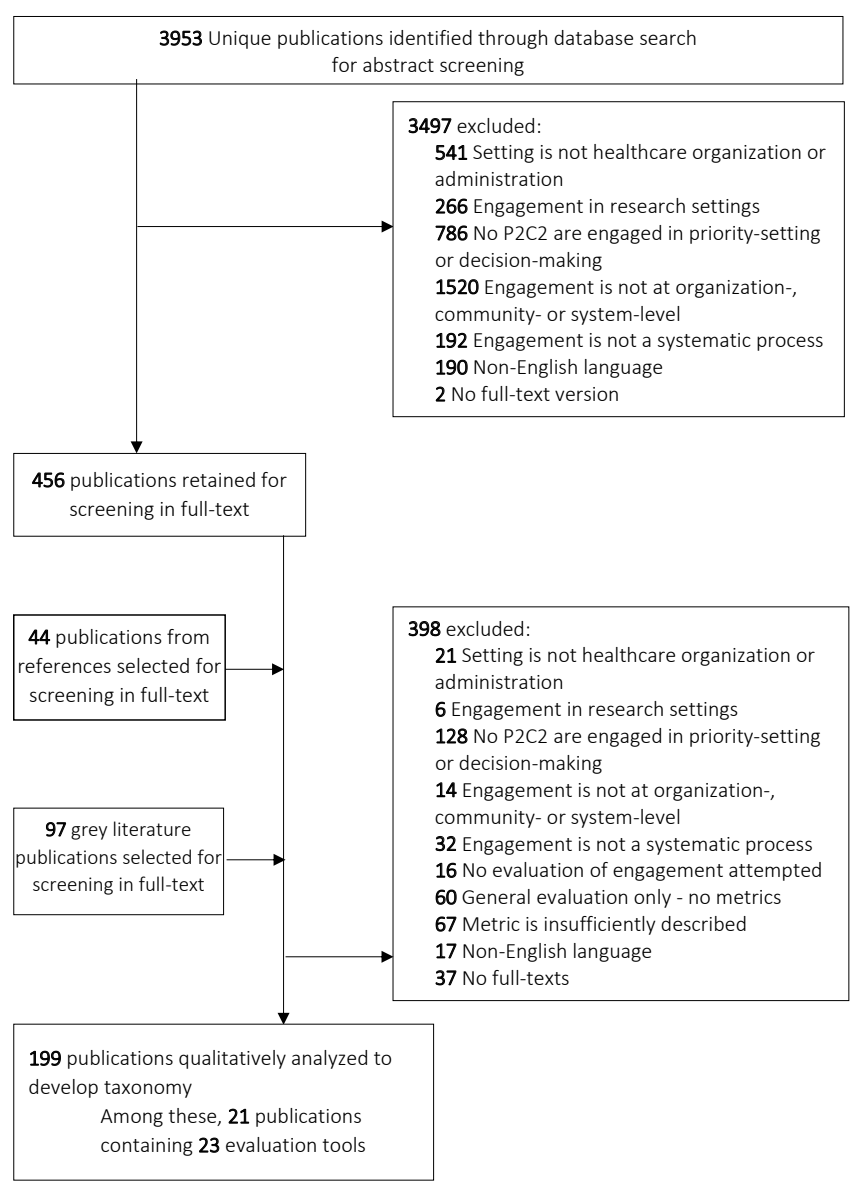

Figure 1. Flow Diagram Describing Publication Selection. 
A publication was excluded if the setting was (1) outside the healthcare sector (eg, urban planning, environmental services, and education sectors, among others, would be excluded); (2) research; or (3) outside of clinical care delivery (eg, public health and/or health promotion programs). Moreover, to be included, publications needed to contain a description of P2C2 engagement in decision-making at the organizational-, community-, or system-level; thus, we excluded publications describing engagement exclusively related to personal medical decisions. Since we also required engagement to be a continuous systematic process (as opposed to episodic or one-off engagement), we excluded publications that did not reference more than one instance of engagement.

First, two reviewers (either VD and RT or VD and MD) independently screened abstracts by applying these exclusion and inclusion criteria. Inter-reviewer disagreement was resolved through discussion involving the third reviewer (either MD or RT). If inclusion or exclusion could not be determined based on an abstract alone, the publication was retained for full-text review. Next, the same selection procedure and criteria were applied for full-text review. Final inclusion eligibility was dependent on the presence of evaluation of engagement, either via a sufficiently detailed definition of a possible measure or via a discrete measure itself. In total 199 publications were retained for this review.

Among these 199, reviewers noted any publications that included an evaluation tool. We defined a tool as a questionnaire, survey, or other evaluative device that a healthcare organization or system could be used with no or minimal modification to evaluate $\mathrm{P} 2 \mathrm{C} 2$ engagement efforts. We identified 21 publications containing 23 evaluation tools.

\section{Developing a Taxonomy of Metrics From the Literature}

When reviewing the 199 publications, reviewers independently annotated each publication for the presence of evaluation metrics. This was done descriptively, via an editing style of qualitative content analysis. ${ }^{30-32} \mathrm{~A}$ reviewer would read the publication in its entirety, highlighting text descriptions of possible evaluation metrics. The reviewer would then inductively apply a descriptive annotation (or "code") of what the evaluation metric intended to measure. To illustrate, if a publication referenced measuring P2C2 participants' "improved knowledge of the healthcare system," this would be descriptively annotated as "knowledge" metric. Next, thematic analysis was used to combine and group similarly themed annotations into one list. Finally, using the accepted distinction between process and outcome metrics in healthcare evaluation, the research team (VD, RT, MD) discussed and reorganized the list into a taxonomy of possible metrics, grouping thematically-related metrics into domains and subdomains of process and outcome categories.

\section{Applying the Taxonomy to Evaluation Tools}

Subsequently, VD and MD, in collaboration, conducted a second qualitative analysis of the included evaluation tools using NVivo Plus (QSR International Pty Ltd, Version 11, 2016). Each tool's questions or survey items were coded according to the taxonomy: firstly, (1) into the process or outcome category; secondly (2) into the metric subdomain, and thirdly (3) as a specific metric within that subdomain. If a question or item was non-specific and could not be coded in steps (2) or (3), it was coded only into the broader category or subdomain. Items could be coded more than once, and coding frequencies were tracked. Based on the resulting frequency histogram, frequencies were transformed into a categorical scale (categories: 1-3 instances, 4-14 instances, or 15 or more instances of coding). Evaluation tools were also descriptively characterized by country, publication date, method of evaluation (quantitative, qualitative or mixed), intended evaluators (leaders, P2C2 representatives, both leaders and representatives, or external evaluators) and setting (healthcare program, individual hospital, healthcare system agency and others). Due to the nature of extracted data, standard procedures to assess quality of studies reporting the metrics or tools were not applicable.

\section{Results}

Overview of the Included Publications

We identified 199 eligible publications, which were qualitatively analyzed to create a taxonomy of possible metrics of $\mathrm{P} 2 \mathrm{C} 2$ engagement in healthcare organization-, community-, and system-level decision-making. Of these, 21 presented 23 distinct evaluation tools. ${ }^{33-53}$ The characteristics of these evaluation tools are in Table 1 (the remaining 178 publications are listed in the online Supplementary file 3).

Identified tools were published between 1973 and 2015. Twelve out 23 were implemented in the United States, three in Canada, three in the United Kingdom, two in Nepal, and the rest were implemented once in other low-middleincome (Djibouti, Honduras, South Africa, or Tanzania) or high-income countries (Ireland or New Zealand). Thirteen tools used mixed method evaluation, six only quantitative evaluation and one only qualitative evaluation. The evaluation was filled out by patient, public, consumer, and community (P2C2) representatives in one tool, by organization leaders in seven tools, by both representatives and leaders in nine tools, and by external evaluators in six tools. The tools were used in diverse settings, from individual hospitals to health systems and programs.

\section{Taxonomy of Metrics}

We organized metrics of $\mathrm{P} 2 \mathrm{C} 2$ engagement into two main categories: outcome metrics and process metrics. ${ }^{54}$ Within each category we identified subdomains which we subsequently clustered into domains based on thematic relatedness. Figure 2 illustrates the taxonomy's domains and subdomains within the categories. Please refer to online Supplementary file 4 for the full taxonomy with metrics forming each subdomain listed.

\section{Outcome Metrics}

We identified 44 unique outcome metrics forming six distinct subdomains. Further, we clustered related subdomains into three domains: (i) internal outcomes, (ii) external outcomes, and (iii) aggregate outcomes. 'Internal outcomes' were those subdomains containing metrics most relevant to, and 
Table 1. Listing of Identified Evaluation Tools and their Basic Characteristics

\begin{tabular}{|c|c|c|c|c|c|c|}
\hline Tool Name (If Applicable), Authors & Country & Year & Setting & $\begin{array}{l}\text { Method of } \\
\text { Evaluation }\end{array}$ & Brief Description & $\begin{array}{l}\text { Who Fills Out } \\
\text { Evaluation }\end{array}$ \\
\hline Metsch and Veney ${ }^{33}$ & USA & 1973 & Individual hospital & Quantitative & $\begin{array}{l}\text { Scoring tool for meeting minutes that assigns weighted categories of } \\
\text { interaction for each consumer recommendation. }\end{array}$ & External evaluators \\
\hline Steckler and Dawson ${ }^{34}$ & USA & 1978 & Health Systems Agency & Quantitative & 38 questions in five items/indices and interview data. Adapted from $\mathrm{m}^{\mathrm{iiv}}$. & $\begin{array}{l}\text { Leaders and } \mathrm{P} 2 \mathrm{C} 2 \\
\text { representatives }\end{array}$ \\
\hline Rifkin, Muller, and Bichmann ${ }^{35}$ & Nepal & 1988 & Healthcare program & Quantitative & Qualitative data scored 1 to 5 in five dimensions using a ranking table. & External evaluators \\
\hline $\begin{array}{l}\text { Consumer Participation Questionnaire, Kent } \\
\text { and Read }{ }^{37}\end{array}$ & New Zealand & 1998 & Mental health services & Mixed method & Yes/No, Likert scale, and discrete choice items. & Leaders \\
\hline El Ansari and Phillips ${ }^{38}$ & South Africa & 2001 & Healthcare program & Quantitative & $\begin{array}{l}\text { 7-point Likert scale covering eight dimensions. Derived from sources evaluating } \\
\text { engagement outside healthcare. }\end{array}$ & $\begin{array}{l}\text { Leaders and } \mathrm{P} 2 \mathrm{C} 2 \\
\text { representatives }\end{array}$ \\
\hline $\begin{array}{l}\text { Partnership self-assessment survey, Shortell } \\
\text { et a }{ }^{39}\end{array}$ & USA & 2002 & Diverse & Quantitative & 5-point Likert scale items. Four components are measured using 1-5 items. & $\begin{array}{l}\text { Leaders and } \mathrm{P} 2 \mathrm{C} 2 \\
\text { representatives }\end{array}$ \\
\hline Halliday et a $\left.\right|^{40}$ & UK & 2004 & Diverse & Mixed method & $\begin{array}{l}\text { 4-point Likert scale (covering nine dimensions) and open-ended questions. } \\
\text { Derived from }{ }^{v-v i} \text {. }\end{array}$ & $\begin{array}{l}\text { Leaders and } \mathrm{P} 2 \mathrm{C} 2 \\
\text { representatives }\end{array}$ \\
\hline Jarrett and Patient Involvement Unit ${ }^{41}$ & UK & 2004 & $\begin{array}{l}\text { Guideline development } \\
\text { group }\end{array}$ & Mixed method & $\begin{array}{l}\text { 5-point Likert scale and interview questions in open-ended fashion, both } \\
\text { evaluating the same aspects. }\end{array}$ & $\begin{array}{l}\text { Leaders and } \mathrm{P} 2 \mathrm{C} 2 \\
\text { representatives }\end{array}$ \\
\hline $\begin{array}{l}\text { A Hospital Self-Assessment Inventory. } \\
\text { Institute for Family-Centered Care }{ }^{22}\end{array}$ & USA & 2004 & Individual hospital & Mixed method & 5-point Likert scale, and 3-point rating system and open-ended notes. & $\begin{array}{l}\text { Leaders and } \mathrm{P} 2 \mathrm{C} 2 \\
\text { representatives }\end{array}$ \\
\hline Well Connected, South et $\mathrm{a}^{43}$ & UK & 2005 & Healthcare program & Quantitative & $\begin{array}{l}\text { 10-point scale covering six dimensions based on three general scoring criteria. } \\
\text { Drawn from tool \#3 and } \text { viviii. }^{\text {. }} \text {. }\end{array}$ & $\begin{array}{l}\text { Leaders and } \mathrm{P} 2 \mathrm{C} 2 \\
\text { representatives }\end{array}$ \\
\hline Grant $^{44}$ & Canada & 2007 & Mental health services & Mixed method & $\begin{array}{l}\text { Yes/No questions, Likert scale questions, and multiple choice items. Modified } \\
\text { by adding questions to tool \#4. }\end{array}$ & Leaders \\
\hline $\begin{array}{l}\text { Evaluation Form, Health and Social Care } \\
\text { Regulatory Forum }\end{array}$ & Ireland & 2009 & Diverse & Mixed method & 5-point Likert and open-ended questions. Derived from ${ }^{\mathrm{ix}}$. & Leaders \\
\hline Draper et $a^{46}$ & $\begin{array}{l}\text { Djibouti, } \\
\text { Honduras, } \\
\text { and Nepal }\end{array}$ & 2010 & Healthcare program & Quantitative & $\begin{array}{l}\text { 5-point scale scoring five factors (tool provides example descriptions for 1-, 3-, } \\
\text { and 5-point scores). Modified \#3, by replacing two domains. }\end{array}$ & External evaluators \\
\hline $\begin{array}{l}\text { PFAC Annual Report Template, Consumer } \\
\text { Health Quality Council HCFA, Massachusetts }{ }^{47}\end{array}$ & USA & 2012 & Individual hospital & Qualitative & Open-ended items and multiple-choice questions. & Leaders \\
\hline
\end{tabular}

892 International Journal of Health Policy and Management, 2018, 7(10), 889-903 


\begin{tabular}{|c|c|c|c|c|c|c|}
\hline Tool Name (If Applicable), Authors & Country & Year & Setting & $\begin{array}{l}\text { Method of } \\
\text { Evaluation }\end{array}$ & Brief Description & $\begin{array}{l}\text { Who Fills Out } \\
\text { Evaluation }\end{array}$ \\
\hline $\begin{array}{l}\text { Consumer Health Quality Council Review } \\
\text { Instrument for } 2011 \text { Reports, Consumer Health } \\
\text { Quality Council HCFA, Massachusetts }{ }^{47}\end{array}$ & USA & 2012 & Individual hospital & Mixed method & Open-ended, multiple choice and Yes/No questions. & External evaluators \\
\hline National Institute for Children's Health Quality ${ }^{48}$ & USA & 2012 & Diverse & Mixed method & $\begin{array}{l}\text { 3-point Likert scale questions with "free-text" field and a set of 5-point Likert } \\
\text { scale questions. Derived from Essential Allies. }{ }^{25}\end{array}$ & Leaders \\
\hline $\begin{array}{l}\text { HCFA Recommended } 2013 \text { PFAC Annual Report } \\
\text { Template HCFA, Massachusetts }{ }^{49}\end{array}$ & USA & 2014 & Individual hospital & Mixed method & Multiple-choice and open-ended questions. & $\begin{array}{l}\text { Leaders and } \mathrm{P} 2 \mathrm{C} 2 \\
\text { representatives }\end{array}$ \\
\hline $\begin{array}{l}\text { HCFA } 2013 \text { PFAC Report Review Tool, HCFA, } \\
\text { Massachusetts }{ }^{49}\end{array}$ & USA & 2014 & Individual hospital & Mixed method & Open-ended, multiple choice and Yes/No questions. & External evaluators \\
\hline $\begin{array}{l}\text { PFAC Council Evaluation. Brigham and Women's } \\
\text { Hospital Center for Patients and Families }{ }^{50}\end{array}$ & USA & 2014 & Individual hospital & Mixed method & 5-point Likert scale and open-ended questions. & $\begin{array}{l}\text { Leaders and } \mathrm{P} 2 \mathrm{C} 2 \\
\text { representatives }\end{array}$ \\
\hline $\begin{array}{l}\text { PPEET, Participant questionnaire, v. 1.0. Abelson } \\
\text { and PPEET Research-Practice Collaborative }{ }^{51}\end{array}$ & Canada & 2015 & Diverse & Mixed method & 5-point Likert scale plus open-ended questions. & $\mathrm{P} 2 \mathrm{C} 2$ representatives \\
\hline $\begin{array}{l}\text { PPEET, Organization questionnaire, v. 1.0. } \\
\text { Abelson and PPEET Research-Practice } \\
\text { Collaborative }\end{array}$ & Canada & 2015 & Diverse & Mixed method & 5-point Likert scale plus open-ended questions. & Leaders \\
\hline $\begin{array}{l}\text { CCP evaluation framework, CCP Steering } \\
\text { Committee }^{52}\end{array}$ & USA & 2015 & Medicaid Managed Care & Quantitative & Review of program websites and documents with Yes/No checkboxes. & External evaluators \\
\hline $\begin{array}{l}\text { National ACO Patient Activation and } \\
\text { Engagement Survey, Shortell et al }{ }^{53}\end{array}$ & USA & 2015 & ACO & Quantitative & 1 to 9 Likert scale and Yes/No items. Part of the National Survey of ACOs. & Leaders \\
\hline
\end{tabular}

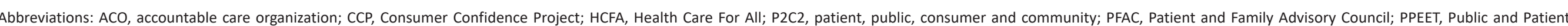
Engagement Evaluation Tool.

References that appear only in Table 1 :

i. Beck A, Bishop P. The Consumer Support Group: A Report to the Board of Trustees, Capitol Area Comprehensive Health Planning Association. Lansing, Michigan, 1973.

i. Douglass C. Representation patterns in community health decision-making. J Health Soc Behav 1973;14(1):80-86. doi:10.2307/2136939.

iii. Douglass C. Effect of provider attitudes in community health decision-making. Med Care 1973;11(2):135-144.

iv. Douglass C. Health Services Planning in the Urban Ghetto: A Comparative Analysis of Eight Model Cities Programs [dissertation]. University of Michigan School of Public Health, Ann Arbor, 1971.

v. Hardy B, Hudson B, Waddington E. What Makes a Good Partnership? A Partnership Assessment Tool. Leeds: Nuffield Institute for Health, Community Care Division, 2000.

vi. World Health Organization/Health Education Board for Scotland. Verona Benchmark: Guide to the Assessment of Good Practice within Partnership Working. 2000.

vii. Yorkshire Forward. Active Partners. Benchmarking Community Participation in Regeneration. Leeds: Yorkshire Forward, 2000.

viii. Funnell R, Olfield K, Speller V. Towards Healthier Alliances: A Tool for Planning, Evaluating and Developing Healthy Alliances. London: Health Education Authority, Wessex Institute for Health, 1995.

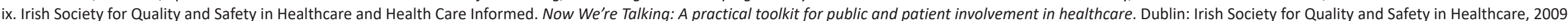




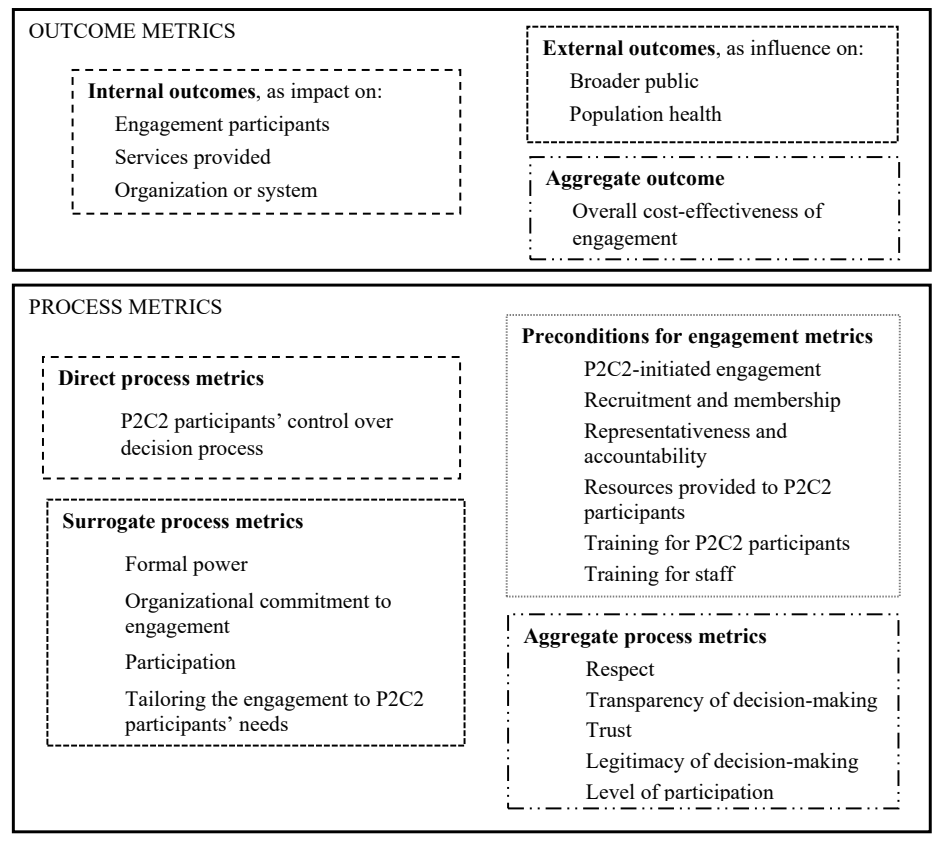

Figure 2. Taxonomy of Metrics: Metrics Categories, Domains and Subdomains. For the full taxonomy with listed metrics forming each subdomain, please refer to online Supplementary file 4.

evaluated within, a healthcare organization or system. This domain included three subdomains: impact on engagement participants themselves (eg, improved knowledge among P2C2 participants), impact on the services provided by the organization or system (eg, improved quality or decreased utilization of services), and impact on the organization or system (on its policies, procedures or resources, eg, redesign of staff roles, or staff training policies, or expanding its patient engagement program).

By contrast, 'external outcomes' were those subdomains containing metrics most relevant beyond the organization or system itself and requiring evaluation outside the organization. This group included two subdomains: influence on the broader public (eg, strengthened public support of the organization) or on population health generally (eg, decreased health inequalities).

Finally, we kept cost effectiveness of engagement as a separate 'aggregate outcome' domain since the overall cost-effectiveness from the standpoint of the healthcare organization or system could take into account all changes (positive or negative) throughout all subdomains.

\section{Process Metrics}

We identified 72 unique process metrics forming 16 subdomains. We clustered related subdomains into four domains: (i) direct process metrics; (ii) surrogate process metrics; (iii) preconditions for engagement metrics; and (iv) aggregate process metrics.

'Direct process metrics' included subdomains that describe the degree of real control that $\mathrm{P} 2 \mathrm{C} 2$ participants have over the decision-making process. For instance, whether P2C2 participants set the agenda, have well-defined roles, or are able to evaluate and revise the decision process itself are all metrics that could be considered as those of direct control over the process. Other examples of such metrics are whether
P2C2 participants are involved in the decision process since its first stages, or P2C2 participants are included in all types of decisions and activities, or $\mathrm{P} 2 \mathrm{C} 2$ participants are allowed the opportunity to finalize the decisions.

By contrast, the domain of 'surrogate process metrics' does not evaluate direct control over decision-making. Instead, surrogate process metrics describe formal attributes of the process. For instance, whether $\mathrm{P} 2 \mathrm{C} 2$ participants hold certain formal positions within the organization, have veto power, or are financially independent of the organization are all metrics of formal attributes that could correlate with direct process control. Attendance of the meetings by P2C2 participants is another example of a surrogate metric in the participation subdomain. Surrogate process metrics also included metrics related to the organizational commitment to engagement, such as the presence of a formal declaration of support for engagement, and metrics identifying whether engagement is tailored to P2C2 participants' needs or beliefs.

'Preconditions for engagement metrics' included subdomains of factors necessary for engagement. ${ }^{55}$ Relevant subdomains included metrics covering the type of recruitment process used to identify P2C2 participants, whether resources (eg, parking, transportation, and/or meals) are provided to the $\mathrm{P} 2 \mathrm{C} 2$ participants, whether training is provided to $\mathrm{P} 2 \mathrm{C} 2$ participants or organizational staff, $\mathrm{P} 2 \mathrm{C} 2$ participants' representativeness and accountability to their constituents, and whether engagement was initiated by P2C2. For instance, under the subdomain of representativeness, metrics could evaluate whether $\mathrm{P} 2 \mathrm{C} 2$ participants are representative of their relevant constituency (eg, a disease group), democratically represent a broader community, or explicitly represent minority, vulnerable or marginalized groups.

Finally, 'aggregate process metrics' included subdomains of metrics that evaluate cross-domain aspects of engagement and provide an overall summary assessment as a result. For 
instance, metrics of trust draw upon different aspects of the preconditions, surrogate measures, and direct measures of the engagement process.

\section{Results of Coding Evaluation Tools According to the Taxonomy Outcome Metrics}

Among 23 identified tools (introduced in Table 1), 13 included at least one question or item coded as an outcome of P2C2 engagement (Table 2). The entire taxonomy contains 44 unique outcome metrics; 22 of these were identified in at least one question or item within a tool. Internal outcomes were more frequently coded than external outcomes.

Individual tools varied in their coverage of outcome metrics, ranging from one item addressing a general outcome measure to 32 coding instances when a tool's questions or items included all six outcome metric subdomains. Six tools included four or more instances of coded outcome metrics. Among the five of these containing 4-14 coding instances, internal outcomes were predominant. All six were designed to be filled out by both leaders and P2C2 representatives (including two separately coded tools that comprise one inventory $\left.\mathrm{y}^{51}\right)$.

\section{Process Metrics}

All 23 identified tools included at least one question or item coded as a process metric of engagement (Table 3). Fifty-six of the 72 unique process metrics described in the taxonomy were present in at least one tool. Direct process metrics evaluating P2C2 control over decision process were identified in every tool. Surrogate process metrics addressing organizational commitment to engagement and participation as well as metrics of preconditions for engagement (ie, resources provided to $\mathrm{P} 2 \mathrm{C} 2$ participants), were the most frequent process metrics.

Individual tools varied in their coverage of process metrics, ranging from one tool that included three instances in three metric subdomains to another tool that included 41 instances within six subdomains of process metrics. Seven tools included 15 or more instances of coded process metrics. Five of them were designed to be filled out by both leaders and $\mathrm{P} 2 \mathrm{C} 2$ representatives and the remaining two by the leaders only. For those seven tools, the most frequently coded subdomains followed the same pattern identified for all the tools.

Thirteen tools included both process and outcomes metrics; three of these tools contained 4-14 instances of outcome metrics and 15 or more instances of coded process metrics. All of these three tools were designed to be filled out by both leaders and $\mathrm{P} 2 \mathrm{C} 2$ representatives.

\section{Discussion}

This systematic review of metrics for evaluating $\mathrm{P} 2 \mathrm{C} 2$ engagement in healthcare organization-, community-, and system-level decision-making produced the following principal findings. First, from our qualitative analysis, we developed a comprehensive taxonomy of 116 possible engagement metrics grouped into distinct domains and subdomains. Second, we identified 23 tools that could be used to evaluate $\mathrm{P} 2 \mathrm{C} 2$ engagement. There was no perfect tool: they varied in their coverage of the taxonomy, in the method used (ie, qualitative versus quantitative) and intended evaluators (leaders, P2C2 representatives, or both, or, alternatively, external experts). Third, parts of the metric taxonomy were absent from all tools.

\section{Taxonomy of Metrics}

The developed taxonomy illustrates that the literature on P2C2 engagement describes a large variety of possible process and outcome metrics. Perhaps reflecting an emphasis on engagement as itself a process, nearly twice as many process metrics (72) were identified compared to outcome metrics (44). Among outcome metrics, more addressed internal outcomes (ie, the effect of $\mathrm{P} 2 \mathrm{C} 2$ engagement on the organization itself, its services, or engagement participants) than external outcomes (ie, the effect of engagement beyond the organization where it occurs).

Among process metrics, we identified four domains of surrogate process metrics. However, analogous to health measures - where surrogate metrics may or may not evaluate the clinically significant endpoint - surrogate engagement process metrics, such as attendance or formal organizational commitment to engagement, may or may not evaluate the engagement process meaningfully.

Finally, among process metrics inquiring into preconditions necessary for engagement process, representativeness and accountability constitute a unique measurement challenge. Deciding on theoretical constructs of representativeness and representatives' accountability and then translating those constructs into a feasible evaluation involving, if needed, the constituents themselves, will require complex multidisciplinary solutions.

For both process and outcomes metrics, aggregate metrics, such as whether P2C2 participants feel generally respected in the engagement process, may be useful as starting points but provide little insight into why this is the case or how to improve the P2C2 engagement. Similarly, evaluations employing a general ladder of participation approach ${ }^{56}$ (which ranges from "manipulation" of $\mathrm{P} 2 \mathrm{C} 2$ participants by the organization to "partnership" to complete P2C2 "control" over the process) may guide an overall engagement approach but fail to provide specific actionable feedback on engagement.

Our taxonomy was developed inductively and has similarities and differences with prior taxonomies or frameworks. ${ }^{57}$ It similarly includes subdomains of transparency, representativeness, and resource support, and attention to $\mathrm{P} 2 \mathrm{C} 2$ participants' control over the decision process (including their early involvement and independence in decision-making). However, consistent with prior reviews, ${ }^{27,28}$ our taxonomy includes attention to evaluating outcomes of engagement and further differentiates and structures engagement process metrics. As a result, the identified metrics provide finer-grained details about both process and outcome evaluation aspects pertaining to $\mathrm{P} 2 \mathrm{C} 2$ engagement.

\section{Existing Tools Measuring P2C2 Engagement}

The identified tools varied methodologically and reflected 
Dukhanin et al

Table 2. Coding Frequencies of Outcome Metrics in the Taxonomy per Evaluation Tool

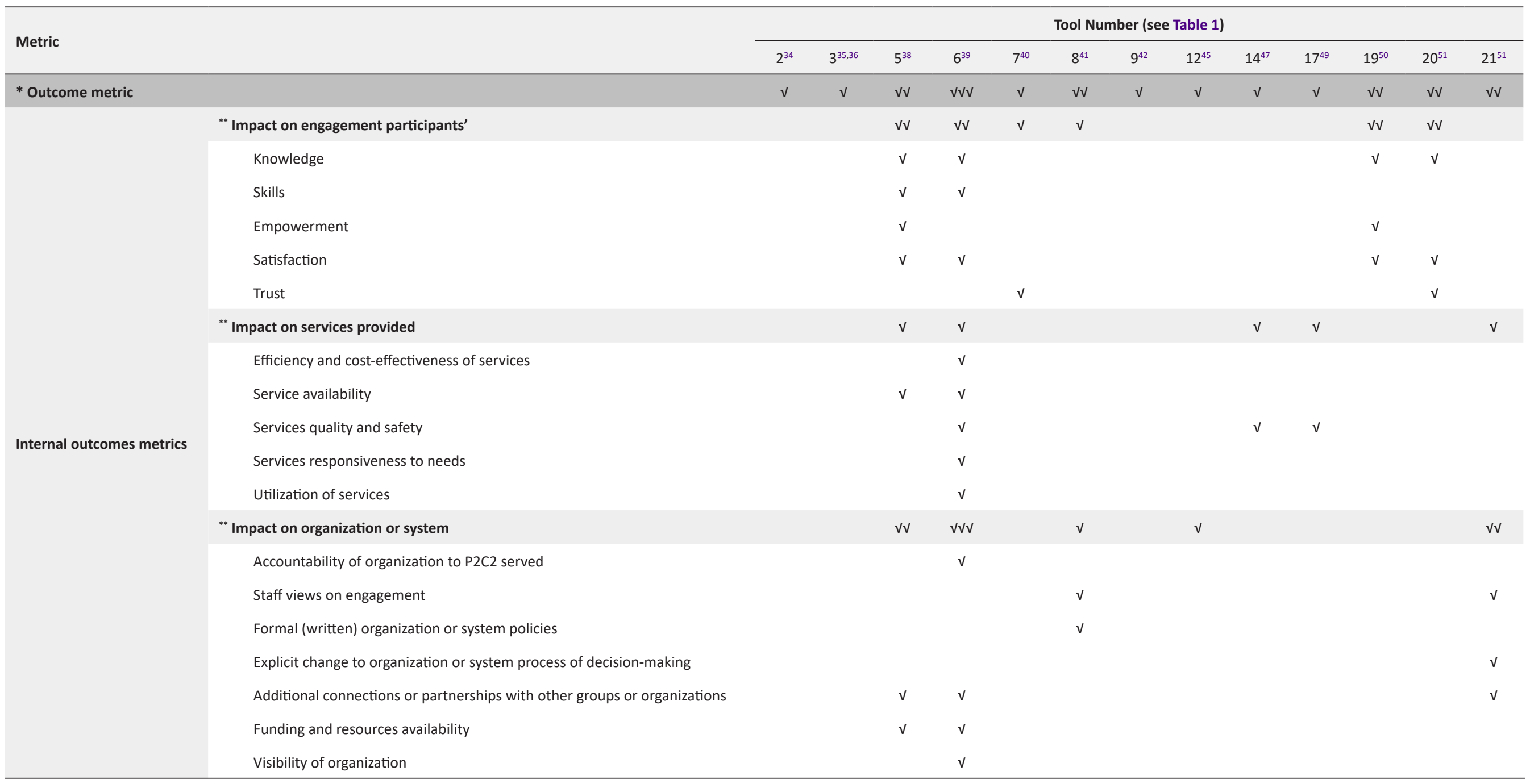

896 International Journal of Health Policy and Management, 2018, 7(10), 889-903 


\section{Table 2. Continued}

\begin{tabular}{|c|c|c|c|c|c|c|c|c|c|c|c|c|c|c|}
\hline \multirow{2}{*}{ Metric } & & \multicolumn{13}{|c|}{ Tool Number (see Table 1) } \\
\hline & & $2^{34}$ & $3^{35,36}$ & $5^{38}$ & $6^{39}$ & $7^{40}$ & $8^{41}$ & $9^{42}$ & $12^{45}$ & $14^{47}$ & $17^{49}$ & $19^{50}$ & $20^{51}$ & $21^{51}$ \\
\hline \multirow{5}{*}{ External outcomes metrics } & "* Influence on broader public's & & & $\mathrm{v}$ & & & & & & & & & & $v$ \\
\hline & Awareness or knowledge of health issues & & & $\mathrm{v}$ & & & & & & & & & & \\
\hline & Support of the organization or system & & & $\mathrm{v}$ & & & & & & & & & & $\mathrm{v}$ \\
\hline & "* Influence on population health & & $\checkmark$ & $v$ & $\checkmark$ & & & & & & & & & \\
\hline & Population health status & & & & $v$ & & & & & & & & & \\
\hline \multicolumn{2}{|c|}{ Aggregate outcome: Overall cost-effectiveness of engagement } & & & & $v$ & & & & & & & & & \\
\hline \multicolumn{2}{|c|}{ Filled out by: External Evaluator } & & $\mathrm{E}$ & & & & & & & & & & & \\
\hline \multicolumn{2}{|l|}{${ }^{* * *}$ Leader } & L & & L & $\mathrm{L}$ & L & L & L & L & L & L & $\mathrm{L}$ & & $\mathrm{L}$ \\
\hline \multicolumn{2}{|c|}{${ }^{* * *} \mathrm{P} 2 \mathrm{C} 2$ representative } & $\mathrm{R}$ & & $\mathrm{R}$ & $\mathrm{R}$ & $\mathrm{R}$ & $\mathrm{R}$ & $\mathrm{R}$ & & & $\mathrm{R}$ & $\mathrm{R}$ & $\mathrm{R}$ & \\
\hline
\end{tabular}

Abbreviation: P2C2; patient, public, consumer and community.

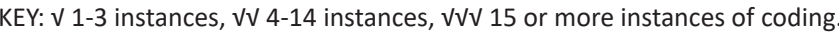

"Row includes instances of items coded only into the outcome metric category when further specification was not possible.

"Row include instances of items coded only into the subdomain when further specification was not possible.

*** Individual coded items could be asked of only leaders, only representatives or both; data shown are for tool as whole.

Metrics absent from all evaluation tools include, by metric subdomain:

- Impact on engagement participants': (1) views; (2) confidence and self-esteem; (3) sense of ownership.

- Impact on services provided: (1) number of complaints on services; (2) sustainability of the services; (3) user experiences with services.

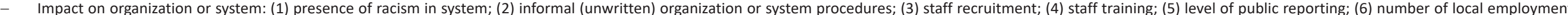

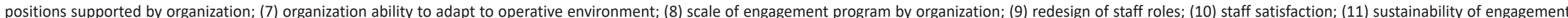
initiative; (12) diversity of funding sources.

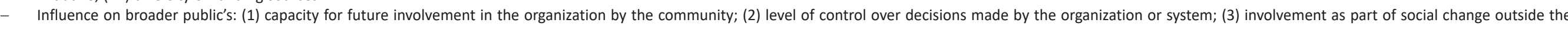
organization; (4) stigmatization of others. 
Dukhanin et al

Table 3. Coding Frequencies of Process Metrics in the Taxonomy Per Evaluation Too

\begin{tabular}{|c|c|c|c|c|c|c|c|c|c|c|c|c|c|c|c|c|c|c|c|c|c|c|c|c|}
\hline \multirow{2}{*}{ Metric } & & \multicolumn{23}{|c|}{ Tool Number (see Table 1) } \\
\hline & & $1^{33}$ & $2^{34}$ & $3^{35,36}$ & $4^{37}$ & $5^{38}$ & $6^{39}$ & $7^{40}$ & $8^{41}$ & $9^{42}$ & $10^{43}$ & $11^{44}$ & $12^{45}$ & $13^{46}$ & $14^{47}$ & $15^{47}$ & $16^{48}$ & $17^{49}$ & $18^{49}$ & $19^{50}$ & $20^{51}$ & $21^{51}$ & $22^{52}$ & $23^{53}$ \\
\hline * Process metric & & $\sqrt{ } \mathbf{V}$ & $\mathbf{V} \mathbf{V}$ & $\mathbf{V} \mathbf{V}$ & $\mathbf{V} \mathbf{V}$ & $\mathbf{V} \mathbf{V}$ & $\mathbf{V} \mathbf{V} \mathbf{V}$ & $\mathbf{V} \mathbf{V}$ & $\mathbf{V} \mathbf{V} \mathbf{V}$ & $\mathbf{V} \mathbf{V} \mathbf{v}$ & $\mathbf{v}$ & $\mathbf{V} \mathbf{V}$ & $\mathbf{V} \mathbf{V} \mathbf{V}$ & $\mathbf{v}$ & $\mathbf{V} \mathbf{V} \mathbf{V}$ & $\mathbf{V} \mathbf{V}$ & $\mathrm{V} \mathbf{V}$ & $\mathbf{V} \mathbf{V} \mathbf{V}$ & $\mathrm{V} \mathbf{V}$ & $\mathbf{V} \mathbf{V} \mathbf{V}$ & $\mathbf{V} \mathbf{V}$ & $\mathbf{V} \mathbf{V}$ & $\mathbf{V} \mathbf{V}$ & $\mathbf{v}$ \\
\hline \multirow{11}{*}{$\begin{array}{l}\text { Direct process } \\
\text { metrics }\end{array}$} & "*2C2 participants' control over decision process: & $v$ & $\mathrm{~V} V$ & $v$ & $v$ & $v$ & $v$ & $\mathrm{~V} V$ & $\sqrt{ } \sqrt{ } \sqrt{ }$ & $\mathrm{V} \vee \mathrm{V}$ & $v$ & $v$ & $\mathrm{~V} V$ & $v$ & $v$ & $v$ & $v$ & $\mathrm{~V} V$ & $v$ & $v$ & $\mathrm{~V} V$ & $\mathrm{~V} V$ & $v$ & $v$ \\
\hline & Agenda setting and time allocation & $v$ & & & & & & & & & & & & $\checkmark$ & $v$ & & & $v$ & $v$ & & & & & \\
\hline & Roles in decision-making are defined & & & & & & $\mathrm{V} V$ & $v$ & & & & & & & $v$ & & $v$ & $v$ & $v$ & & & & $v$ & \\
\hline & Independence in decision-making & & & & & & & & & & & & & $v$ & & & & & & & & & & \\
\hline & Involvement throughout types of decision activities & $\checkmark$ & & $v$ & $v$ & & $v$ & & & $\mathrm{~V} V \mathrm{~V}$ & $v$ & $\mathrm{~V} v$ & $v$ & $v$ & $\mathrm{~V} V$ & & $v$ & $v$ & $v$ & & & $v$ & & $\checkmark$ \\
\hline & Involvement throughout stages of decision process & & & $v$ & & & & & $v$ & & & & & $\checkmark$ & & & & & & & & $\checkmark$ & & \\
\hline & Perceived influence on decision-making process & & $\mathrm{V} V$ & & & $v$ & $v$ & & $\mathrm{~V} v$ & & & & & & $v$ & & & $\checkmark$ & & $v$ & $\mathrm{~V} V$ & & & \\
\hline & Involvement in finalizing decisions & & & & & & & & & & & & & $\checkmark$ & & & & & & & & & & \\
\hline & Control over the meeting minutes & & & & & & & & & & & & & & $\checkmark$ & & & $v$ & & & & & & \\
\hline & Assurance of follow-up commitment/translation into action & & & & & & & & & & & & & & & $v$ & & & & & & $\mathrm{~V} v$ & & \\
\hline & $\begin{array}{l}\text { Revision process (for changing decisions or handling } \\
\text { complaints) }\end{array}$ & & & $v$ & & & & & & & & & & & & & & & & & & & & \\
\hline \multirow{10}{*}{$\begin{array}{l}\text { Surrogate process } \\
\text { metrics }\end{array}$} & ${ }^{* *}$ Formal power ${ }^{a}$ & & & $v$ & v & & & & & $v$ & $v$ & $v$ & & $v$ & $v$ & $v$ & $v$ & $\checkmark$ & $v$ & & & & & \\
\hline & ${ }^{*}$ Organizational commitment to engagement ${ }^{a}$ & & $\mathrm{~V} V$ & & $v$ & $v$ & $\mathrm{~V} V$ & $v$ & $v$ & $\mathrm{~V} V$ & $v$ & & $\mathrm{~V} V$ & & & & $\mathrm{~V} v$ & & $v$ & & & $\mathrm{~V} V$ & & \\
\hline & "* Participation: & & $\mathrm{v} v$ & & & $v$ & $\mathrm{~V} v$ & $v$ & & $v$ & $\checkmark$ & & & $v$ & $\checkmark$ & $v$ & & $\checkmark$ & & $v$ & & & & $v$ \\
\hline & Activeness of participation & & & & & & & & & & & & & $v$ & & & & & & & & & & $v$ \\
\hline & Equality of participation (among P2C2 participants) & & $v$ & & & $v$ & $v$ & & & & & & & $\checkmark$ & & & & & & $\checkmark$ & $v$ & & & \\
\hline & Attendance of engagement participants & & & & & & & & & & & & & & $v$ & & & & & & & & & \\
\hline & Regularity of meetings & & & & & & & & & $v$ & & & & & $v$ & $v$ & & $v$ & & $v$ & & & & \\
\hline & P2C2 participants' readiness and attitudes towards engagement & & $v$ & & & $\checkmark$ & $v$ & $v$ & & & & & & & & & & & & & & & & \\
\hline & ${ }^{* *}$ Tailoring the engagement to $\mathrm{P} 2 \mathrm{C} 2$ participants & & & & & & & & & & & & & & & & $v$ & & & & & & & \\
\hline & Cultural beliefs and practices & & & & & & & & & & & & & & & & $v$ & & & & & & & \\
\hline
\end{tabular}

898 International Journal of Health Policy and Management, 2018, 7(10), 889-903 


$\begin{array}{llll}\text { Metric } & \text { Tool Number (see Table 1) }\end{array}$

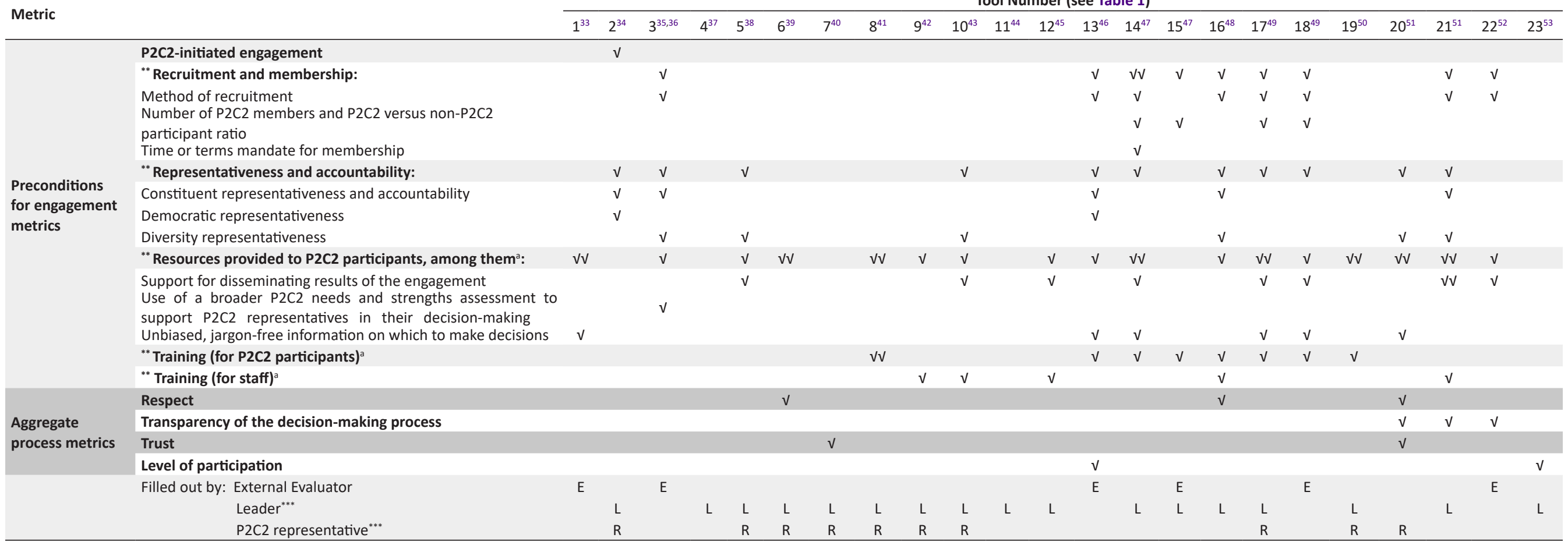

Abbreviation: P2C2; patient, public, consumer and community.

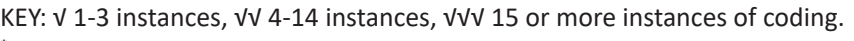

"Row includes instances of items coded only into the outcome metric category when further specification was not possible.

"Row include instances of items coded only into the subdomain when further specification was not possible.

"** Individual coded items could be asked of only leaders, only representatives or both; data shown are for tool as whole.

${ }^{a}$ For brevity not all coded metrics are shown. For the full list of metrics, see the table in online Supplementary file 5.

Some metrics were absent from all evaluation tools. These are available in Supplementary file 5. 
greater emphasis on processes as compared to outcomes. Measuring outcomes of engagement is difficult in part because there may or may not be a proven causal connection between engagement and outcomes of interest. Consequently, many tools rely on measuring perceived benefits of engagement. However, meaningful engagement is more than mere perception; real outcomes (ie, documented changes in policies, procedures, or programs) should be preferred over perceived ones (ie, whether engagement participants or leaders believe they are making a difference). At the same time, the absence of real outcomes in tools may not be surprising; evaluating certain real outcomes (eg, cost) may not require a tool per se when this information is available by other means. Finally, several tools highlight how qualitative methods can complement the assessment of engagement process.

It is important to note metrics which are underemphasized or absent from all tools. Regarding outcomes, improved trust in the organization may be widely perceived as a potential benefit of P2C2 engagement, ${ }^{58}$ but it was only measured by two tools. Neither did any tool measure sustainability of engagement (understood as the ability to maintain engagement with specific $\mathrm{P} 2 \mathrm{C} 2$ participants over time) or the capacity to increase or scale engagement in other parts of the healthcare organization or system. Regarding processes, agenda-setting and time allocation decisions, which are considered key aspects of $\mathrm{P} 2 \mathrm{C} 2$ engagement ${ }^{59}$ that help mitigate power imbalances, were evaluated in only five tools, and $\mathrm{P} 2 \mathrm{C} 2$ participants' involvement in finalizing decisions was evaluated in only one. Debate intensity, which was proposed in the 1970s as a measure of consumer input, ${ }^{60}$ was completely absent.

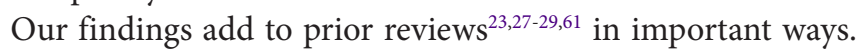
Expanding the date range of our search identified additional evaluation tools. Four of the 23 tools were published in 2015 , suggesting that this is an area of active research and development, and three tools were available before 1990. A notable example is Steckler and Dawson, ${ }^{34}$ who in 1978 published an evaluation of consumer participation in US Health Systems Agencies (HSAs). HSAs were geographically defined agencies that made decisions about healthcare planning and resource use and were legislatively required to have consumer participation. ${ }^{62}$ Steckler and Dawson's evaluation relied on a structured questionnaire and interview data from both consumer participants and staff leaders.

Practice, Policy and Research Implications

Our systematic review has implications for the implementation of $\mathrm{P} 2 \mathrm{C} 2$ engagement and for future research. For those seeking to evaluate $\mathrm{P} 2 \mathrm{C} 2$ engagement in real-world settings, several tools exist to get started. They vary methodologically, with some methods (eg, qualitative interviews and analysis) requiring more time, resources and expertise than others. Although, in our view, no evaluation tool is perfect and a comprehensive mapping of tools to all possible engagement contexts would be beyond the scope of this review, we were able to make three observations and practical suggestions to help potential evaluators in choosing among tools using Tables 2 and 3.
First, in certain healthcare contexts, significant emphasis may be placed on whether P2C2 engagement demonstrates positive impact via quantitatively-measured outcomes (such as improving individuals' knowledge or improving healthcare service quality, among others). In those contexts, two tools stand out in Table 2 as being most comprehensive in the area of outcomes. ${ }^{38,39}$ Second, while most included tools paid significant attention to process measures, again two stood out in Table 3. One was a quantitative assessment tool ${ }^{46}$ used for healthcare programs and based on the decades of work from Rifkin and colleagues, ${ }^{35}$ and another was a more qualitative assessment designed for individual hospitals in the United States. ${ }^{47}$ Third, it is important to note that some tools should be used together. For instance, the Participant questionnaire and Organization questionnaire of the Public and Patient Engagement Evaluation tool together provide a mixed method evaluation that is capable of assessing the perspectives of both $\mathrm{P} 2 \mathrm{C} 2$ representatives and organizational leaders in different contexts. $^{51}$

We can also interpret our taxonomy of metrics, which was developed inductively from the literature through the lens of Arnstein's "ladder of participation." ${ }^{6}$ This theoretical approach characterizes levels of engagement (ranging from, eg, manipulation to information to partnership to citizen control) and suggests that the goal of engagement is to increase P2C2 control over the decision process. Through Arnstein's lens, we can suggest what may be the essential components of evaluation and how to advance evaluation over time (Figure 3).

These suggestions are tailored to a healthcare system or organization's level of maturity for P2C2 engagement. First, although completely defining the discrete levels of maturity is beyond the scope of this paper, implicit in this figure (Figure 3 ) is the idea that systems or organizations should endeavor to progress from Level 1 (basic maturity, ie, ready to involve P2C2 participants) to Level 2 (intermediate maturity, ie, some experience with P2C2 engagement) to Level 3 (fully mature, ie, significant experience). Second, even though some tools identified in our review included only the system or organization leaders' perspectives, in our view, any evaluation must solicit the $\mathrm{P} 2 \mathrm{C} 2$ perspective on engagement, and when systems or organizations evaluate cost-effectiveness, they should include the time and resource costs accruing to P2C2 participants. Third, as organizations become more mature, relative emphasis on different process and outcome metrics changes. For instance, mature systems and organizations should shift away from surrogate measures of P2C2 participants control over decision-making toward direct control measures; likewise, they should be more attentive to external outcomes. Finally, as systems and organizations mature, they should consider using external evaluators, who could yield additional insights into the $\mathrm{P} 2 \mathrm{C} 2$ engagement process.

From our review we suggest three priority areas of future research. First, additional research is needed to better understand the validity and reliability of tools and metrics in different healthcare contexts. The lack of evidence of rigorous testing of the identified tools for methodological quality and 


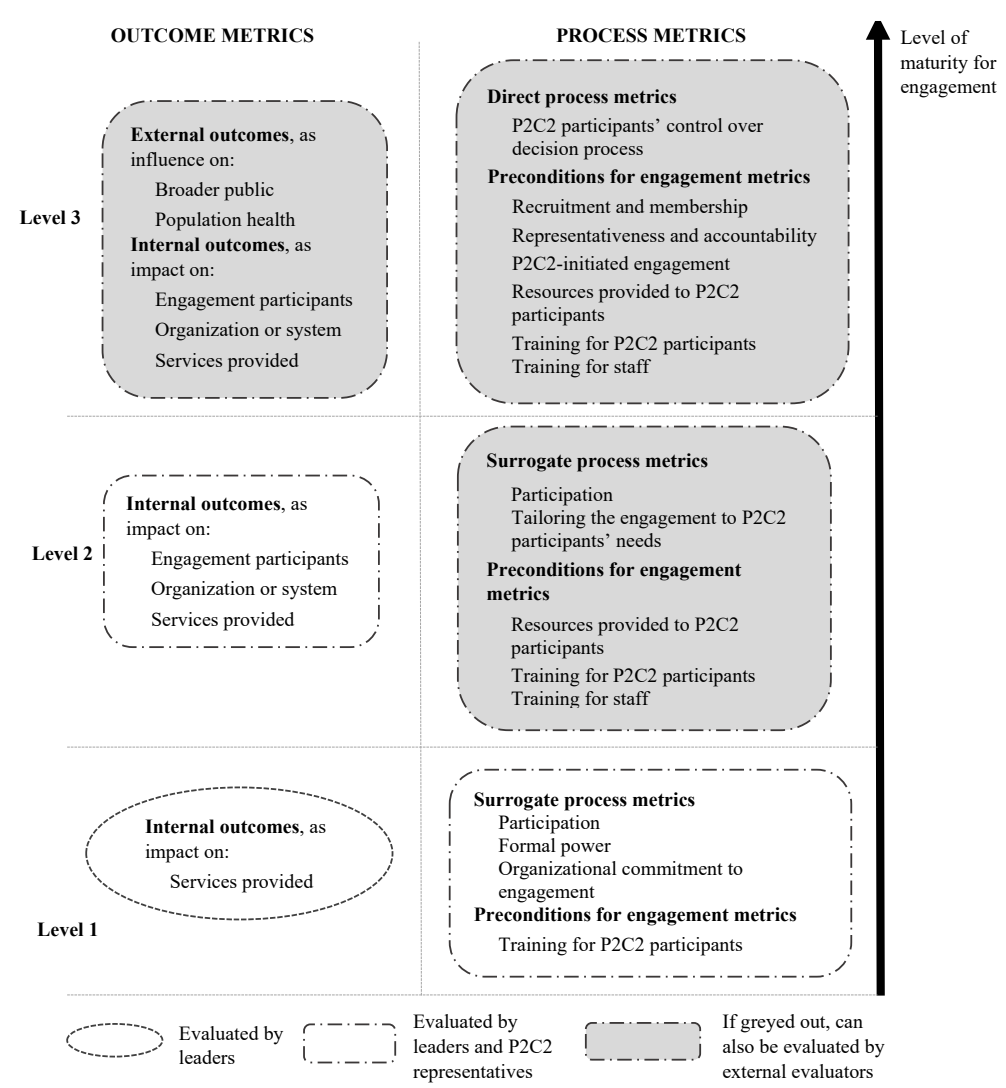

Figure 3. Proposed Metric Subdomains for Evaluating Patient, Consumer, Public and Community (P2C2) Engagement According to System- or Organizational Maturity for Engagement.

psychometric properties was noticeable; it suggests a need to increase testing and reporting of these factors. Second, our taxonomy and the diversity of metrics employed by the tools argue for a consensus-building process to identify and disseminate core metrics. Our taxonomy provides a starting point for that process, which itself must include P2C2 participants. As research into valid and reliable engagement metrics proceeds, attention will need to turn to comparative evaluation of the metrics (eg, to find the best way to measure representativeness) and the use of those metrics for comparative evaluation of different methods of engagement (eg, single representatives versus patient councils). Finally, new tools may be needed in order to capture parts of the taxonomy not currently represented in existing tools.

\section{Strengths and Limitations}

This review has several strengths. The search strategy was designed to be as broad and inclusive as possible in both terminology and date range. The resulting taxonomy was constructed not from any single theoretical approach to P2C2 engagement but instead from an inductive data-driven analysis and comprehensive literature review. Moreover, the findings from this review may inform other fields of $\mathrm{P} 2 \mathrm{C} 2$ engagement; for example, the identified process metrics might be of interest to those evaluating $\mathrm{P} 2 \mathrm{C} 2$ engagement in research, environmental or other social policy settings.

Like all studies, ours has limitations. First, we focused on organization-, community-, and system-level decision-making in healthcare administration and organization. We excluded engagement, for instance, in other health-related fields, such as public health, health promotion or health education, and in other non-health fields. These were excluded to focus our review, and because existing engagement frameworks consider engagement in organization-, community-, and system-level decisions as a conceptually distinct activity from engagement in more societal-level decisions. ${ }^{2}$ While the translation of evaluation concepts and tools from these other fields could be possible and useful, that task is beyond the scope of this systematic review. Second, although our search strategy was designed to be comprehensive, certain terms (such as "health system") may have different meanings in different countries and contexts. This could have affected our results. Moreover, terminology surrounding $\mathrm{P} 2 \mathrm{C} 2$ engagement is imprecise (eg, patients versus consumers versus community members), and at present there appears to be no consensus regarding the aims and objectives of this type of engagement. This presents challenges to a literature search and systematic review. For instance, "community" engagement may be distinct from "patient" engagement in some circumstances (eg, when a healthcare organization wants to engage directly with a community that has historical distrust of that organization). Finally, because our review employed qualitative analysis, it may have introduced subjectivity in our categorization of metrics.

\section{Conclusions}

Significant progress is being made in the evaluation of P2C2 engagement in healthcare organization- and system-level 
decision-making. The comprehensive taxonomy developed here suggests that organizations have ample process and outcome metrics as well as evaluation tools from which to choose when evaluating engagement efforts. Future research is needed to compare existing tools in practice, to develop new tools to capture all relevant metrics, and to use these tools to compare the effectiveness of different methods of engagement. This review lays the foundation for doing so.

\section{Acknowledgments}

The work has been funded by a grant from the U.S. Agency for Healthcare Research and Quality (1K08HS023684-01). The funder did not play any role in the study design, collection, analysis, and interpretation of data, in the writing of the report; and in the decision to submit the article for publication.

\section{Ethical issues}

Not applicable.

\section{Competing interests}

Authors declare that they have no competing interests.

\section{Authors' contributions}

MD conceived of and designed the study. VD conducted the literature search, all authors performed study selection and data extraction, VD and MD synthesized the data. All authors contributed to the interpretation of the results. VD and MD were major contributors in writing the manuscript. All authors revised the manuscript, read and approved the final manuscript.

\section{Authors' affiliations}

${ }^{1}$ Department of Health Policy and Management, Johns Hopkins Bloomberg School of Public Health, Baltimore, MD, USA. 'National Journal, Washington, DC, USA. 3Johns Hopkins Berman Institute of Bioethics, Baltimore, MD, USA. ${ }^{4}$ Division of General Internal Medicine, Department of Medicine, Johns Hopkins School of Medicine, Baltimore, MD, USA.

\section{Supplementary files}

Supplementary file 1. Databases search strategy.

Supplementary file 2. Gray literature sources.

Supplementary file 3 . List of all publications included in the qualitative analysis to develop the taxonomy.

Supplementary file 4. Taxonomy of metrics of patient, public, consumer and community (P2C2) engagement in healthcare system-, community-, and organization-level decision-making.

Supplementary file 5 . Full version of Table 3.

\section{References}

1. Declaration of Alma-Ata. WHO Chron. 1978;32(11):428-430.

2. Carman $\mathrm{KL}$, Dardess $\mathrm{P}$, Maurer $\mathrm{M}$, et al. Patient and family engagement: A framework for understanding the elements and developing interventions and policies. Health Aff. 2013;32(2):223231. doi:10.1377/hlthaff.2012.1133

3. Charles C, DeMaio S. Lay participation in health care decision making: a conceptual framework. J Health Polit Policy Law. 1993;18(4):881-904. doi:10.1215/03616878-18-4-881

4. An act to promote cost containment, transparency and efficiency in the delivery of quality health care, Enacted in the Acts of 2008, The General Laws of Massachusetts, Ch. 305, Sect. 11/53F (2008).

5. DeCamp M, Sugarman J, Berkowitz S. Meaningfully Engaging Patients in ACO Decision-making. Am $J$ Accountable Care. 2015;3(2):30-33.

6. Pearson SD, Sabin JE, Emanuel EJ. No Margin, no Mission: Healthcare Organizations and the Quest for Ethical Excellence. Oxford, New York: Oxford University Press; 2003.

7. Egener BE, Mason DJ, McDonald WJ, et al. The charter on professionalism for health care organizations. Acad Med. 2017. doi:10.1097/ACM.0000000000001561

8. Danis M, Solomon M. Providers, payers, the community, and patients are all obliged to get patient activation and engagement ethically right. Health Aff. 2013;32(2):401-407. doi:10.1377/ hlthaff.2012.1081

9. Galiher CB, Needleman J, Rolfe AJ. Consumer participation. HSMHA Health Rep. 1971;86(2):99-106.

10. Martin GP. Whose health, whose care, whose say? Some comments on public involvement in new NHS commissioning arrangements. Crit PubHealth. 2009;19(1):123-132. doi:10.1080/09581590802385672

11. Anton S, McKee L, Harrison S, Farrar S. Involving the public in NHS service planning. J Health Organ Manage. 2007;21(4-5):470-483. doi:10.1108/14777260710778989

12. Culyer AJ. Involving stakeholders in healthcare decisions-the experience of the National Institute for Health and Clinical Excellence (NICE) in England and Wales. Healthc Q. 2005;8(3):5660. doi:10.12927/hcq..17155

13. Frankish CJ, Kwan B, Ratner PA, Higgins JW, Larsen C. Challenges of citizen participation in regional health authorities. Soc Sci Med. 2002;54(10):1471-1480. doi:10.1016/S0277-9536(01)00135-6

14. Thurston WE, MacKean G, Vollman A, et al. Public participation in regional health policy: A theoretical framework. Health Policy. 2005;73(3):237-252. doi:10.1016/j.healthpol.2004.11.013

15. Church J, Saunders D, Wanke M, Pong R, Spooner C, Dorgan M. Citizen participation in health decision-making: Past experience and future prospects. J Public Health Policy. 2002;23(1):12-32. doi:10.2307/3343116

16. Preston R, Waugh H, Larkins S, Taylor J. Community participation in rural primary health care: Intervention or approach? Aust J Prim Health. 2010;16(1):4-16. doi:10.1071/PY09053

17. Bath J., Wakerman J. Impact of community participation in primary health care: What is the evidence? Aust J Prim Health. 2015;21(1):28. doi:10.1071/PY12164

18. Coney S. Effective Consumer Voice and Participation for New Zealand: A Systematic Review of the Evidence: Discussion Document. Auckland: New Zealand Guidelines Group; 2004.

19. Bolsewicz Alderman K, Hipgrave D, Jimenez-Soto E. Public engagement in health priority setting in low- and middle-income countries: current trends and considerations for policy. PLoS Med. 2013;10(8):e1001495. doi:10.1371/journal.pmed.1001495

20. Kohler JC, Martinez MG. Participatory health councils and good governance: healthy democracy in Brazil? Int J Equity Health. 2015;14(1):21. doi:10.1186/s12939-015-0151-5

21. O'Meara WP, Tsofa B, Molyneux S, Goodman C, McKenzie FE. Community and facility-level engagement in planning and budgeting for the government health sector--a district perspective from Kenya. Health Policy. 2011;99(3):234-243. doi:10.1016/j. healthpol.2010.08.027

22. Meads GD, Griffiths FE, Goode SD, Iwami M. Lessons from local engagement in Latin American health systems. Health Expect. 2007;10(4):407-418. doi:10.1111/j.1369-7625.2007.00468.x

23. Mitton C, Smith N, Peacock S, Evoy B, Abelson J. Public participation in health care priority setting: A scoping review. Health Policy. 2009;91(3):219-228. doi:10.1016/j.healthpol.2009.01.005

24. Agency for Healthcare Research and Quality. Strategy 1: Working With Patients and Families as Advisors. http://www.ahrq.gov/ professionals/systems/hospital/engagingfamilies/strategy $1 /$ index. html. Accessed September 5, 2015.

25. Jeppson ES, Thomas J. Essential Allies: Families as Advisors. Washington, DC: Institute for Family-Centered Care; 1995.

26. Coulter A. Patient engagement-what works? J Ambul Care Manage. 2012;35(2):80-89.doi:10.1097/JAC.0b013e318249e0fd

27. Conklin A, Morris Z, Nolte E. What is the evidence base for public involvement in health-care policy?: Results of a systematic scoping review. Health Expect. 2015;18(2):153-165. doi:10.1111/hex.12038

28. Crawford MJ, Rutter D, Manley $C$, et al. Systematic review of involving patients in the planning and development of health care. $\mathrm{Br}$ Med J. 2002;325(7375):1263-1265. doi:10.1136/bmj.325.7375.1263

29. Abelson J, Montesanti S, Li K, Gauvin F, Martin E. Effective Strategies for Interactive Public Engagement in the Development of Healthcare Policies and Programs. Ottawa, ON: Canadian Health Services Research Foundation; 2010.

30. Corbin JM, Strauss AL, Strauss AL. Basics of Qualitative Research: Techniques and Procedures for Developing Grounded Theory. Thousand Oaks, CA: Sage Publications Inc; 2008. 
31. Crabtree BF, Miller WL. Doing Qualitative Research. Newbury Park, CA: Sage Publications, Inc; 1992.

32. Sandelowski M. Whatever happened to qualitative description? Res Nurs Health. 2000;23(4):334-340. doi:10.1002/1098240X(200008)23:4<334::AID-NUR9>3.0.CO;2-G

33. Metsch JM, Veney JE. Measuring the Outcome of Consumer Participation. J Health Soc Behav. 1973;14(4):368-374

34. Steckler A, Dawson L. Determinants of consumer influence in a health systems agency. Health Educ Monogr. 1978;6(4):378-393.

35. Rifkin SB, Muller F, Bichmann W. Primary health care: On measuring participation. Soc SciMed. 1988;26(9):931-940.

36. Schmidt DH, Rifkin SB. Measuring participation: Its use as a managerial tool for district health planners based on a case study in Tanzania. Int J Health Plann Manage. 1996;11(4):345-358.

37. Kent H, Read J. Measuring consumer participation in mental health services: Are attitudes related to professional orientation? Int J Soc Psychiatry. 1998;44(4):295-310. doi:10.1177/002076409804400406

38. El Ansari AW, Phillips C.J. Interprofessional collaboration: A stakeholder approach to evaluation of voluntary participation in community partnerships. J Interprof Care. 2001;15(4):351-368. doi:10.1080/13561820120080481

39. Shortell SM, Zukoski AP, Alexander JA, et al. Evaluating partnerships for community health improvement: Tracking the footprints. $J$ Health Polit Policy Law. 2002;27(1):49-91. doi:10.1215/03616878-27-1-49

40. Halliday J, Asthana SNM, Richardson S. Evaluating partnership: the role of formal assessment tools. Evaluation. 2004;10(3):285-303. doi:10.1177/1356389004048279

41. Jarrett $\mathrm{L}$, Patient Involvement Unit. A report on a study to evaluate patient/carer membership of the first NICE Guideline Development Groups. London: National Institute for Clinical Excellence (NICE); 2004. Accessed September 5, 2015

42. Institute for Family-Centered Care. Patient- and Family-Centered Care: A Hospital Self-Assessment Inventory. Bethesda, MD: Institute for Family-Centered Care; 2004. Accessed September 5, 2015

43. South J, Fairfax P, Green E. Developing an assessment tool for evaluating community involvement. Health Expect. 2005;8(1):6473. doi:10.1111/j.1369-7625.2004.00313.x

44. Grant J. The participation of mental health service users in Ontario, Canada: A Canadian Application of the Consumer Participation Questionnaire. Int J Soc Psychiatry. 2007;53(2):148-158. doi:10.1177/0020764006074557

45. Health and Social Care Regulatory Forum. Framework for Public and Service User Involvement in Health and Social Care Regulation in Ireland. http://www.mhcirl.ie/File/Framework_Pub_SU.pdf. Accessed September 5, 2015.

46. Draper AK, Hewitt G, Rifkin S. Chasing the dragon: Developing indicators for the assessment of community participation in health programmes. Soc Sci Med. 2010;71(6):1102-1109. doi:10.1016/j. socscimed.2010.05.016

47. Consumer Health Quality Council Health Care For All, Massachusetts. Health Care for All: Patients and Families Improving Care. Patient and Family Advisory Councils: A Review of 2011 PFAC Reports. http://www.ipfcc.org/bestpractices/Review-of-PFAC2011-Reports.pdf. Accessed September 5, 2015.
48. National Institute for Children's Health Quality. Creating a Patient and Family Advisory Council: A Toolkit for Pediatric Practices. http://www.nichq.org/ /media/files/resources/pfac\%20toolkit/pfac resources.ashx. Accessed September 5, 2015.

49. Health Care for All, Massachusetts. PFAC 2014. A Review of 2013 Massachusetts Patient \& Family Advisory Council Reports. https://www.hcfama.org/sites/default/files/2014_pfac_report_final. pdf. Accessed September 5, 2015

50. Brigham and Women's Hospital Center for Patients and Families. Patient and Family Advisory Council (PFAC) Report Submitted September 30, 2014. https://www.hcfama.org/sites/default/files/ brigham and womens dph report sept 2014.pdf. Accessed September 5, 2015.

51. Abelson J, PPEET Research-Practice Collaborative. The Public and Patient Engagement Evaluation Tool. https://fhs.mcmaster.ca/ publicandpatientengagement/ppeet.html. Accessed September 5 , 2015.

52. Consumer Confidence Project Steering Committee. Consumer Confidence Project: Report of Pilot Results. http://www. mentalhealthportland.org/wp-content/uploads/2015/08/ConsumerConfidence-Project-Report-of-Pilot-Results.pdf. Accessed September 5, 2015.

53. Shortell SM, Sehgal NJ, Bibi S, et al. An early assessment of accountable care organizations' efforts to engage patients and their families. Med Care Res Rev. 2015;72(5):580-604. doi:10.1177/1077558715588874

54. Rowe G, Frewer LJ. Evaluating public-participation exercises: a research agenda. Sci Technol Hum Val. 2004;29(4):512-556. doi:10.1177/0162243903259197

55. Abelson J. Understanding the role of contextual influences on local health-care decision making: case study results from Ontario, Canada. Soc Sci Med. 2001;53(6):777-793. doi:10.1016/S02779536(00)00386-5

56. Arnstein SR. A ladder of citizen participation. J Am Inst Plann 1969;35(4):216-224. doi:10.1080/01944366908977225

57. Rowe G, Marsh R, Frewer LJ. Evaluation of a Deliberative Conference. Sci Technol Hum Val. 2004;29(1):88-121. doi:10.1177/0162243903259194

58. Tenbensel T. Interpreting public input into priority-setting: the role of mediating institutions. Health Policy. 2002;62(2):173-194.

59. Abelson J, Forest PG, Eyles J, Smith P, Martin E, Gauvin FP. Deliberations about deliberative methods: issues in the design and evaluation of public participation processes. Soc Sci Med. 2003;57(2):239-251. doi:10.1016/S0277-9536(02)00343-X

60. Worley CG, Mohrman SA, Nevitt JA. Large group interventions: An empirical field study of their composition, process, and outcomes. $J$ App/Behav Sci. 2011;47(4):404-431. doi:10.1177/0021886311410837

61. Abelson J, Li K, Wilson G, Shields K, Schneider C, Boesveld S. Supporting quality public and patient engagement in health system organizations: development and usability testing of the public and patient engagement evaluation tool. Health Expect. 2016;19(4):817. doi:10.1111/hex.12378

62. Werlin SH, Walcott A, Joroff M. Implementing formative health planning under PL 93-641. N Engl J Med. 1976;295(13):698-703. doi:10.1056/NEJM197609232951304 